\title{
¡No hay dos sin tres!
}

\section{Things come in threes!}

\section{Sr. Director:}

Ya sabes que hoy se ha realizado el TERCER TRASPLANTE de cara, y si algo resulta casi más excepcional que el hecho médicoquirúrgico, es la poquísima trascendencia mediática que hasta el momento existe.

Yo me pregunto si esto es bueno o es malo, y digo esto porque personalmente estoy ávido de noticias al respecto, no sólo - que sí también- desde el punto de vista médico y de especialista del territorio trasplantado, sino como ciudadano, y además, sobre todo en este último sentido, incluso me veo con todos los derechos para que se me informe - con la prudencia que corresponda- de los aspectos más sobresalientes de este TERCER TRASPLANTE en la mayor brevedad posible. Y todo porque noticias de esta envergadura son las que de verdad pueden darnos grandes satisfacciones humanas, al observar cómo un grupo notable de organismos y profesionales que trabajan con seriedad, ilusión y en equipo son capaces de realizar actos todavía históricos, en momentos en los que la humanidad está en crisis económica pero para nada en crisis de continua superación, que es lo que verdaderamente le hace falta al mundo.

El TERCER TRASPLANTE, decía, iya es historia! Incluso si los resultados no fueran los esperados. Y digo esto porque, para organizar un evento de estas características hay que hacer un extraordinario esfuerzo, incluso mayor que el propio trasplante, que con sus dificultades no deja de ser una acto meramente médico, y para su resolución seguro que no faltan capacidades científicas y artesanales de los profesionales que lo han llevado a efecto en Barcelona, o de los que hubieran podido realizarlo en otro lugar. No pocas veces hemos dicho en diferentes foros que lo más difícil para un cirujano es programar y preparar con sosiego un acto quirúrgico, hecho por cierto incomprendido y muy devaluado por autoridades y responsables, que sólo están pendientes de las listas de espera, como si el acto médico-quirúrgico no fuera más que -como incluso en el caso que nos ocupa- una extraordinaria rutina.

Estoy seguro de que todos los profesionales estaban más que entrenados para la cirugía, pero para lo que nunca está entrenado un médico es para que se mida su dedicación y su profesionalidad sólo por los resultados. Creo que no conozco a ninguno de los profesionales que han participado en el trasplante, pero estoy seguro -y pondría las manos en el fuegode que se han dejado la piel en esta cirugía, de la misma manera que cuando intervienen cirugías habituales pero no por ello de menor entidad (para cada enfermo y su familia, la operación más importante es la que le van a hacer o están haciendo a su ser querido).

Sirva pues este TERCER TRASPLANTE para recordar a propios y extraños que todos los días, en todos los sitios del mundo, 
miles de profesionales de la sanidad luchan por librar a los enfermos de su enfermedad. Y no porque los médicos - por referirnos al estamento que primero nos viene a la cabezaseamos extraordinarios y excepcionales seres humanos dotados de grandes capacidades de todo tipo, espirituales, científicas o artesanales, sino simple y llanamente porque los médicos sólo queremos seguir aprendiendo cada día un poco más, lo que sin duda redundará en beneficios incalculables para la sociedad.

Para terminar, que todo el mundo sepa que lo mejor para ayudar a los enfermos es facilitar el aprendizaje permanente y sin escatimar medios a los profesionales, y esto no siempre va aparejado a que se les pague más: va sobre todo aparejado fundamentalmente al respeto por parte de toda la sociedad, lo mismo que debería ocurrir con los padres y los maestros.
Mientras esto no quede claro, será fácil que muchas posibles vocaciones no se acerquen a la medicina o a la enseñanza, para que trasmitan a sus allegados primero y al ambiente la inquietud y el amor a la profesión médica y los otros pilares señalados, padres y maestros.

¡Enhorabuena ya, desde la noche siguiente, a los que han hecho posible el TERCER TRASPLANTE de cara en España, mucho antes de saber de la evolución clínica del paciente, que seguro que es buena, pase lo que pase!

\section{Francisco Hernández Altemir}

Miembro Fundador de las Sociedades Europeas de Cirugía Oral y Maxilofacial y de Cabeza y Cuello, y Miembro de Honor de la Sociedad Española de Cirujanos de Cabeza y Cuello 